\title{
Sorption-Desorption Behavior and Characterization of Cyclophosphamide
}

\author{
K. V. PAVAN*, M. ARTHANAREESWARI, A. RAVIKIRAN and P. KAMARAJ \\ Department of Chemistry, SRM University, Kattankulathur, Tamilnadu, India \\ kommavarapu.pavan@gmail.com
}

Received 3 February 2013 / Accepted 15 February 2013

\begin{abstract}
Cyclophosphamide is a nitrogen mustard alkylating agent from the oxazophorines group. The primary metabolite of cyclophosphamide (CP, 1), i.e. 4-hydroxy-CP 2, has high pharmacological activity, but it is a very unstable compound. During processing and storage of the dry powder formulation, a glassiness or stickiness could be acquired by the premix composition giving an unattractive material with inferior solubility characteristics and decreased potency. This deterioration was more pronounced if it exceeds normal storage temperature. In this present exertion sufficient data on cyclophosphamide characterization is provided and the sorption-desorption studies were performed to comprehend the hygroscopicity temperament of the drug. Cyclophosphamide was characterized using powder x-ray diffraction, differential scanning calorimetry and thermogravimetry. Characterization data lend a hand in identifying and understanding the physical properties of the drug. The water sorption-desorption profile provides key information related to the physical stability of solid forms, especially hydrates (Cyclophosphamide). We scrutinized the moisture uptake of samples at various relative humidity and temperatures using gravimetric methods and can fully characterize the drug. Sorption-desorption studies were performed using gravimetric vapour sorption technique and found the critical factors in storage and stability of the drug.
\end{abstract}

Keywords: Formulation, Characterization, Powder X-ray diffraction, Differential scanning calorimetry, Thermogravimetry, Gravimetric vapour sorption

\section{Introduction}

Many pharmaceutical drugs and drug products are moisture sensitive in nature. So any information about their structural changes because of moisture is of immense importance when processing and storing of drug substances and also the choice of packing material depends on the stability of the drug at room temperature. So establishment of stability details is very important before handling these types of products. While handling these moisture sensitive drug substances the mechanical treatment can affect the physical properties ${ }^{1}$. So it is very clear that physical characterization of active pharmaceutical ingredient is essential to the successful development of the final drug product ${ }^{2}$. It is known that pharmaceuticals solids can exist in more than one form and the different solid form of a drug can display different physical and chemical properties. The most thermodynamically stable form is taken

$†$ Presented to the National Conference on Chemistry Solutions at SRM University, India 
for development in to final drug dosage form ${ }^{3,4}$. The most important techniques used for the drug characterization studies and understanding the physical properties are $\mathrm{x}$-ray powder diffraction (XRPD), thermal techniques including differential scanning calorimetry (DSC) and thermo-gravimetric analysis (TGA). To understand the hygroscopicity behavior of the molecule vapour sorption techniques are used.

The aim of this study was to determine the stability ranges of monohydrate form of cyclophosphamide as function of relative humidity. Different analytical techniques were used to characterize the drug and to interpret the different moisture behavior of the drug. Cyclophosphamides are cytotoxic chemotherapy agents similar to mustard gas. Although their common use is medicinal, in principle these compounds can also be deployed as chemical warfare agents ${ }^{5}$. It is an alkylating agent used in cancer treatment that attaches an alkyl group $(\mathrm{CnH} 2 \mathrm{n}+1)$ to $\mathrm{DNA}^{6}$. The main use of cyclophosphamide is with other chemotherapy agents in the treatment of lymphomas a type of blood cancer, some forms of brain cancer, leukemia ${ }^{7}$ and some solid tumors ${ }^{8}$. Molecular Formula of Cyclophosphamide monohydrate is $\mathrm{C}_{7} \mathrm{H}_{15} \mathrm{Cl}_{2} \mathrm{~N}_{2} \mathrm{O}_{2} \mathrm{P} . \mathrm{H}_{2} \mathrm{O}$ and the systematic name is 2-[bis(2-chloroethyl) amino]tetrahydro-2H-1,3,2-oxazaphosphorine 2-oxide monohydrate. The structural formula of cyclophosphamide monohydrate is shown in Figure 1.

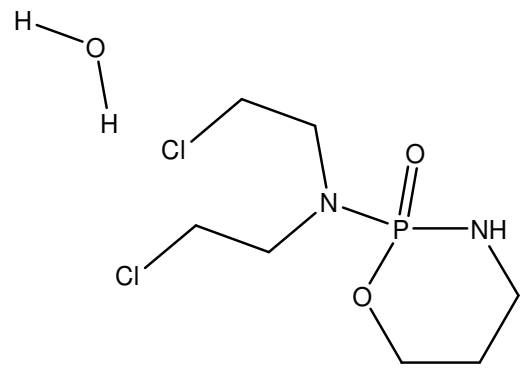

Figure 1. Chemical structure of cyclophosphamide monohydrate

\section{Experimental}

Mettler Toledo DSC $831^{\mathrm{e}}$ with STARe software was used for recording and processing DSC thermogram of cyclophosphamide monohydrate. For the identification about $3.4817 \mathrm{mg}$ of the drug was weighed accurately using high sensitive microbalance (Mettler Toledo XP2U, Max $2.1 \mathrm{~g}-\mathrm{Min}-1 \mu \mathrm{g}$ ) and heated in a closed aluminum pan at a programmed rate of $10{ }^{\circ} \mathrm{C} \mathrm{min}{ }^{-1}$ in the temperature range from $25{ }^{\circ} \mathrm{C}$ to $350{ }^{\circ} \mathrm{C}$ under nitrogen flow of $40 \mathrm{~mL} \mathrm{~min}^{-1}$. Empty aluminum pan was used as a reference.

\section{Thermogravimetry-differential thermal analysis (TG-DTA)}

Mettler Toledo TGA/SDTA (Model 851e) with STARe software was used for recording and processing TG-DTA thermogram of cyclophosphamide monohydrate. Accurately weighed powder of $2.5418 \mathrm{mg}$ was taken into a alumina crucibles $(70 \mu \mathrm{L})$, heated at a programmed rate of $10{ }^{\circ} \mathrm{C} \mathrm{min}-1$ in the temperature range from $25{ }^{\circ} \mathrm{C}$ to $150{ }^{\circ} \mathrm{C}$ under nitrogen flow of $40 \mathrm{~mL} \mathrm{~min}^{-1}$.

\section{$X$-ray powder diffraction (XRPD) analysis}

X-ray powder diffraction patterns were measured by Bruker D8 advance X-ray diffractometer with $\mathrm{Cu}$ anode and Lynx eye detector. For the identification of cyclophosphamide monohydrate the samples were scanned from $3^{0} 2 \theta$ to $45^{0} 2 \theta$, with step 
size $0.01^{0} 2 \theta$ and time per step of $0.1 \mathrm{sec}$. The instrument was operated at $40 \mathrm{kV}$ generator voltage and $40 \mathrm{~mA}$ generator current. Variable divergent slit and Anti scattering slit were used of $\mathrm{V}_{20} \mathrm{~mm}$, Nickel filter was used in secondary beam path. Eva software was used for data processing and evaluation.

\section{Gravimetric vapour sorption analysis}

Gravimetric vapour sorption instruments are entrenched methods for determining vapour sorption isotherms. These instruments measure the sample mass change as the vapour environment surrounding the sample is transformed. An increase in mass is typically associated with vapour sorption, while a decrease is caused by vapour desorption. The vapour concentration around the sample is controlled by mixing saturated and dry carrier gas streams using electronic mass flow controllers ${ }^{9}$. In this study, all experiments were performed using a Hiden Isochema IGAsorp. The system utilizes a large capacity microbalance $(5 \mathrm{~g})$ with a resolution of $0.1 \mu \mathrm{g}$ and excellent long-term stability $( \pm 1 \mu \mathrm{g})$ and high-resolution humidity control with a minimum step change of $0.2 \% \mathrm{RH}$.

\section{Results and Discussion}

\section{Characterization of the drug}

\section{Thermal analysis}

Two individual heaters were used in order to monitor the individual heating rates. A control system regulates the temperature difference between sample and reference. If any difference is detected the individual heating's will be corrected such that the temperature was kept the same in both pans. That is, when an endothermic process occurs, the instrument delivers the compensation energy which must be given in order to maintain equal temperature in both pans. Thermal analysis reveals the melting point of the drug which is at about $49.44{ }^{\circ} \mathrm{C}$ and it is in the range of $49.44{ }^{\circ} \mathrm{C}-55.32{ }^{\circ} \mathrm{C}$. The thermogram of Cyclophosphamide is shown in the Figure 2.

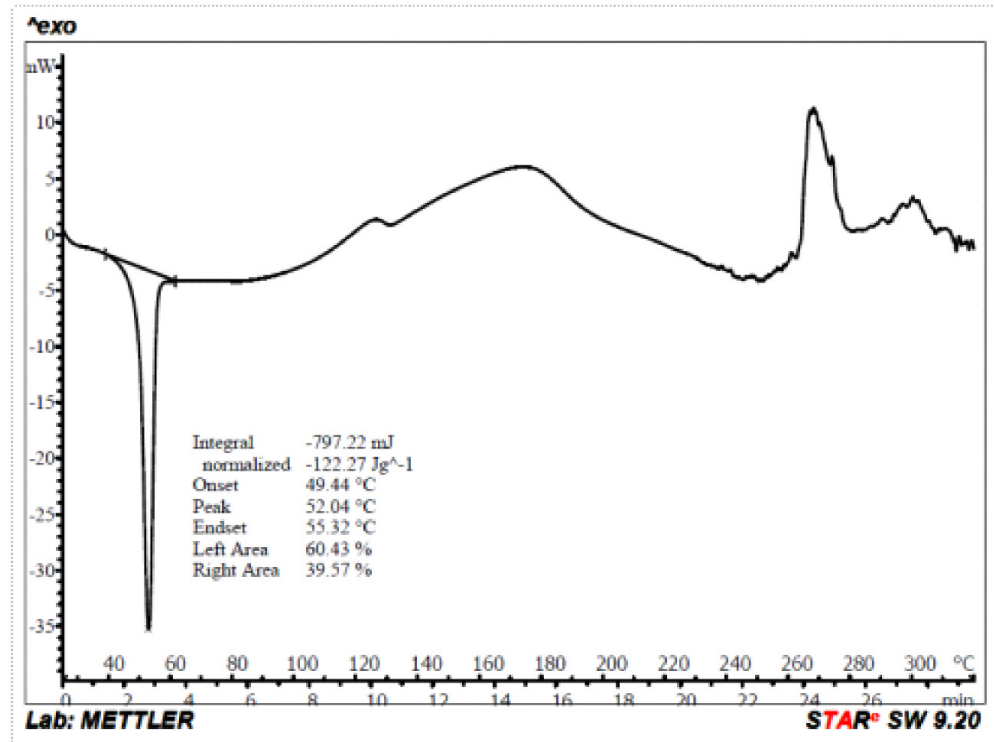

Figure 2. DSC thermogram of cyclophosphamide monohydrate 
Thermogravimetric analysis (TGA) is an analytical technique used to determine a material's thermal stability and its fraction of volatile components by monitoring the weight change that occurs as a specimen is heated. The measurement was normally carried out in nitrogen inert atmosphere and the weight were recorded as a function of increasing temperature. The weight loss of cyclophosphamide was found to be $0.6417 \%$ and the total weight loss was found to be $6.1576 \%$. The TGA thermogram along with second derivative thermal analysis curve is shown in the Figure 3.

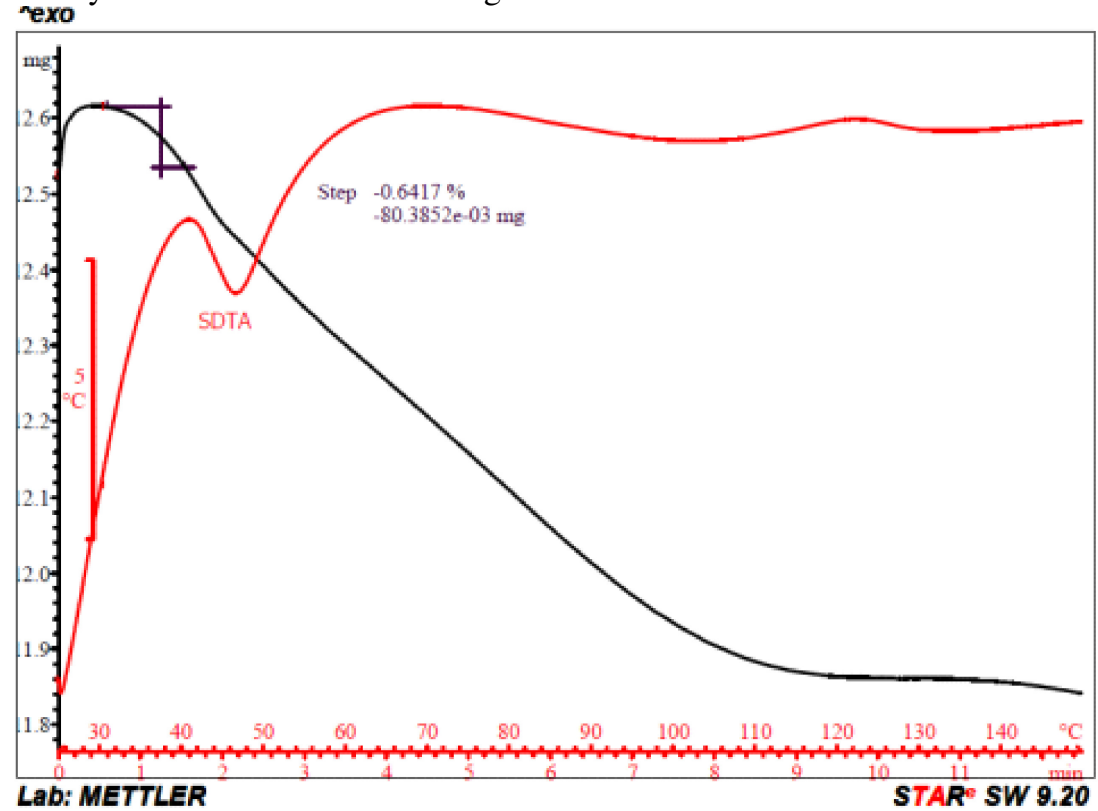

Figure 3. TGA thermogram of cyclophosphamide monohydrate

Powder x-ray diffraction (PXRD)

From the x-ray diffraction technique the characteristic peaks of cyclophosphamide was found at about 7.010, 10.991, 14.054, 14.735, 17.797, 18.444, 18.920, 20.418, 21.234, $21.949,26.713,28.244$ and $33.655^{\circ} 2 \theta$ and the diffractogram is shown in the Figure 4.

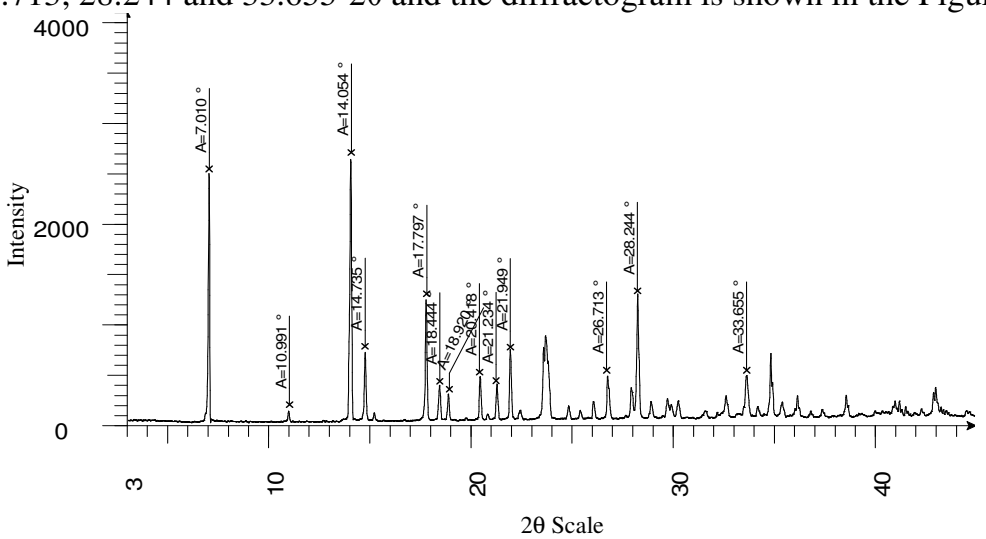

Figure 4. Diffraction pattern of cyclophosphamide monohydrate 
Using variable temperature P-XRD diffraction patterns were collected for sample at $0 \%$ RH for 2 hours and sample at $0 \%$ RH for 14 hours. It was observed that the drug loses its crystallinity. When the sample was observed visually it was in liquefied state indicating it's in stability at $0 \% \mathrm{RH}$. The overlaid diffractogram indicating this event is shown in Figure 5.

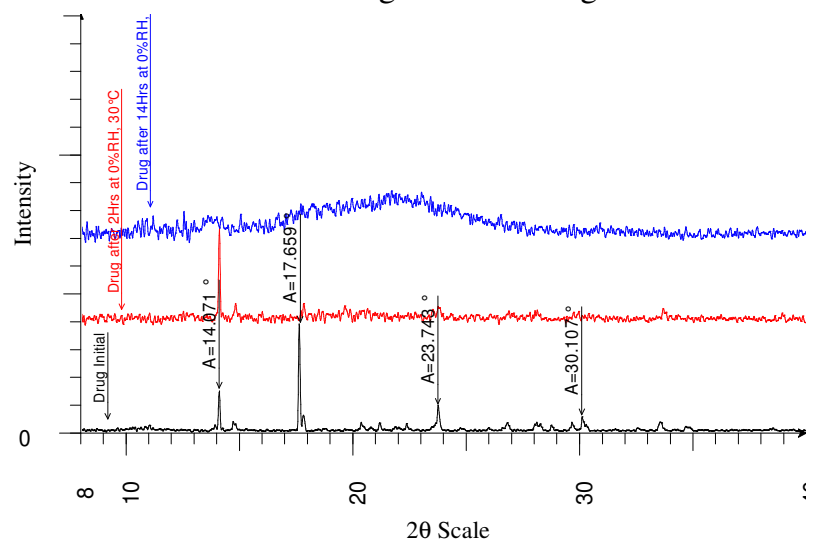

Figure 5. The overlaid diffraction pattern of the drug at $0 \%$ RH for 2 hours and 14 hours

\section{Gravimetric vapour sorption studies}

Vapor sorption analysis is of significant interest to the pharmaceutical industry. Moisture content can have a strong effect on the structure and properties of materials and water sorption measurements are used to determine the amorphous phase content of active ingredients. Vapor sorption measurements also allow the study of hydrate and solvate formation, respectively. Figure 6 shows the vapour sorption isotherm for cyclophosphamide monohydrate showing the various steps involved to run the experiment.

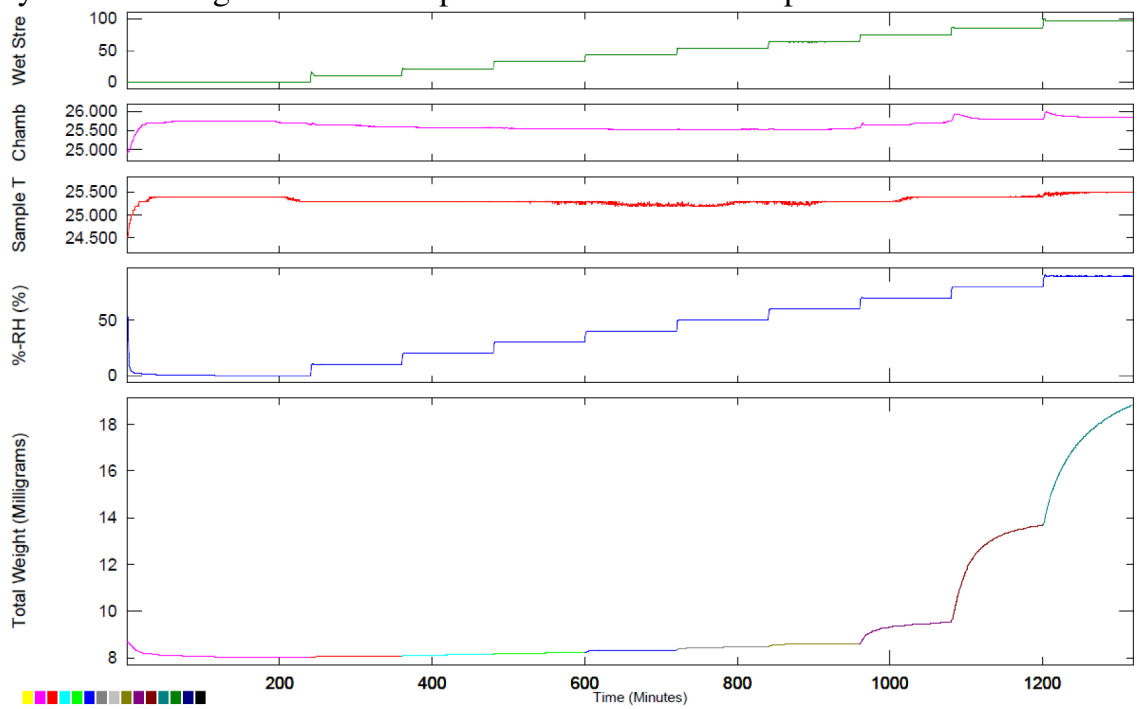

Figure 6. Vapour sorption isotherm of the drug

In this study desorption for $4 \mathrm{~h}$ at $0 \%$ relative humidity was performed and sorption from $0 \%$ to $90 \%$ was performed at an interval of 2 hours. Weight lose at each intervals were 
calculated. At $0 \%$ RH $7.88 \%$ loss in weight, $10 \%$ RH $7.32 \%$ loss in weight, $20 \%$ RH $6.55 \%$ loss in weight, $30 \% \mathrm{RH} 6.17 \%$ loss in weight, $40 \% \mathrm{RH} 4.30 \%$ loss in weight, $50 \% \mathrm{RH}$ $2.73 \%$ loss in weight, $60 \%$ RH $1.42 \%$ loss in weight, $70 \%$ RH $9.49 \%$ gain in weight, $80 \%$ RH $57.09 \%$ gain in weight and at $90 \%$ RH $116.4 \%$ gain in weight is observed respectively indicating the high instability of the molecule. Figure 7 shows the sorption desorption study of cyclophosphamide at 0-90\% RH at ambient temperature.

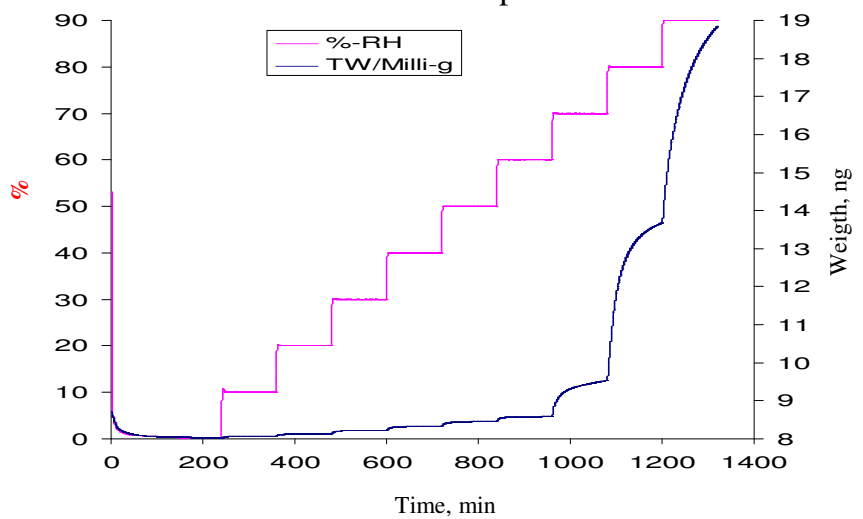

Figure 7. Sorption-desorption isotherm of the drug

\section{Conclusion}

From the above study the drug cyclophosphamide monohydrate is well characterized using analytical tools like DSC, TG-DTA and XRPD. From vapour sorption desorption studies it is observed that the drug is highly sensitive and unstable to moisture below $25 \% \mathrm{RH}$ and above $30 \% \mathrm{RH}$. So the storage should be done between these relative humidity values. Below and above these values the drug is converting in to a sticky material.

\section{References}

1. $\quad$ Ensio L and Vesa-Pekka L, Int J Pharma., 1998, 163(1-2), 49-62.

2. Byrn, R. Pfeiffer, Ganey M, Hoiberg C and Poochikian G, Pharm Res., 1995, 12(7), 945-954.

3. Haleblian J and McCrone W, J Pharm Sci, 1969, 58, 911-929.

4. Bugay E, Advanced Drug Delivery Reviews, 2001, 48, 43-65.

5. Takimoto $\mathrm{C} \mathrm{H}$ and Calvo E, $11^{\text {th }}$ ed., Principles of Oncologic Pharmacotherapy, in Pazdur R, Wagman L D, Camphausen K A and Hoskins W J, (Eds)., Cancer Management: A Multidisciplinary Approach, 2008.

6. Bigner D D and Zalutsky M R, U.S. Patent Application, 2006, 11/416,633.

7. Shanafelt T D, Lin T S, Geyer S M, Zent C S, Leung N, Kabat B, Bowen D, Grever M R, Byrd J C and Kay N E, Cancer, 2007, 109(11), 2291-2298.

8. Young S D, Whissell M, Noble J C S, Cano P O, Lopez P G and Germond C J, Clin Can Res., 2006, 12(10), 3092-3098.

9. Raula J, Thielmann F, Kansikas J, Hietala S, Annala M, Seppälä J, Lähde A and Kauppinen EI, Pharm Res., 2008, 25(10), 2250-2261 